\title{
Development of a Gondola Type External Wall Painting Robot
}

\author{
Toshikazu Miyajima*, Shin Terauchi*, Kazuhiko Arai**, and \\ Takezou Miyamoto*** \\ * Technical Research Institute, Kajima Corporation, 2-19-1, Tobitakyu, Chofu- \\ shi, Tokyo 182, JAPAN \\ ** Architectural Technology Division, Kajima Corporation, 6-15-16, Akasaka, \\ Minato-ku, Tokyo 107, JAPAN \\ ${ }^{* * *}$ Mechanical and Equipment Department, Kajima Corporation, 1-1-5, Moto- \\ akasaka, Minato-ku, Tokyo 107, JAPAN
}

\begin{abstract}
The painting of building external walls is usually performed using a gondola or scaffolding, involves working at considerable heights, and is an unclean job due to windblown paint spray. Recently too, there have been problems involving quality due to the lack of skilled painters. As a solution to such problems, painting robots have been developed for the external painting of large scale structures such as nuclear power stations or warehouse buildings. Until now, painting robots have been developed for use with mast type mobile staging. However, in order to provide a more general system and achieve improved work efficiency, a new painting robot was developed that can be suspended from gondola staging. This paper gives a general outline of the newly developed robot and reports the results of field trials that were carried out to verify its effectiveness.
\end{abstract}

\section{INTRODUCTION}

Automation and robotics have entered various fields of the construction industry, and paint work is no exception. Generally, painting of the external walls of buildings is carried out using scaffolding or a gondola. The task involves working at considerable heights, and is an unclean job due to windblown paint spray. Recently too, there have been problems involving quality due to the lack of skilled painters, and there is clearly an urgent need to improve the working environment and quality of the work being carried out.

In order to overcome such problems and to achieve an increase in the overall efficiency, painting robots have been developed for the painting of concrete 
external walls of large scale buildings such as nuclear power stations or warehouse buildings.

Until now, painting robots for use with mast type mobile staging have been developed[1], and although the use of these robots achieved the anticipated improvements in efficiency and quality, problems remain in providing a more generally applicable type of robot that could be used over a wider range of applications. Based on the research previously carried out, a new type of robot that can be suspended from gondola staging was developed, with the aim of providing a more generally applicable device and achieving further increases in efficiency.

This paper contains a description of the newly developed robot, and reports on field trials carried out on the buildings of a nuclear power station.

\section{THE PAINTING ROBOT}

\subsection{Area of Application of the Robot}

The painting robot was primarily developed for application to large scale concrete structures such as nuclear power stations or warehouse buildings where a high degree of efficiency can be achieved with mainly repair paint work.

The robot was designed for use with paints such as JIS A 6021 "Liquid-applied Compounds for Waterproofing Membrane Coating of Roof " that are widely used on buildings of this type. However, unlike general industrial paints, this paint is made up of four different paint materials; under coat, intermediate coat (body coat), body texture coat, and top coat; each of which has different characteristics. It is therefore difficult to achieve good quality paint work even for an experienced craftsman.

\subsection{Outline of the Robot}

As can be seen in Figure 1, the robot performs the painting work suspended below gondola staging capable of lateral movement of the type employed in general construction work. The specification of the robot is shown in Table 1 .

The structure of the robot includes a spray gun and gun driving device, measures the distance from the gun to the surface being painted and maintains a set distance. In addition, to prevent unevenness due to overlap of spray passes, the gun incorporates an oscillating mechanism to achieve improved quality.

The robot is designed to perform under coat, intermediate coat, body texture coat, and top coat while being operated by a craftsman using an operating panel (touch panel type) from the ground, while controlling the downward movement of the gondola.

The robot incorporates the following features:

i) The robot may be utilized in any location where gondola staging can be used, and by removal of the robot, normal gondola work can be carried out.

ii) Uniform quality of a standard equivalent to that of an experienced craftsman is achieved.

iii) Productivity is about four times that of manual labor.

iv) The thickness of the intermediate paint film is simply controlled by controlling the pressure of the paint supply pump.

v) Body texture coat such as beaded spray is performed by controlling the air pressure to suit the required beading diameter. 


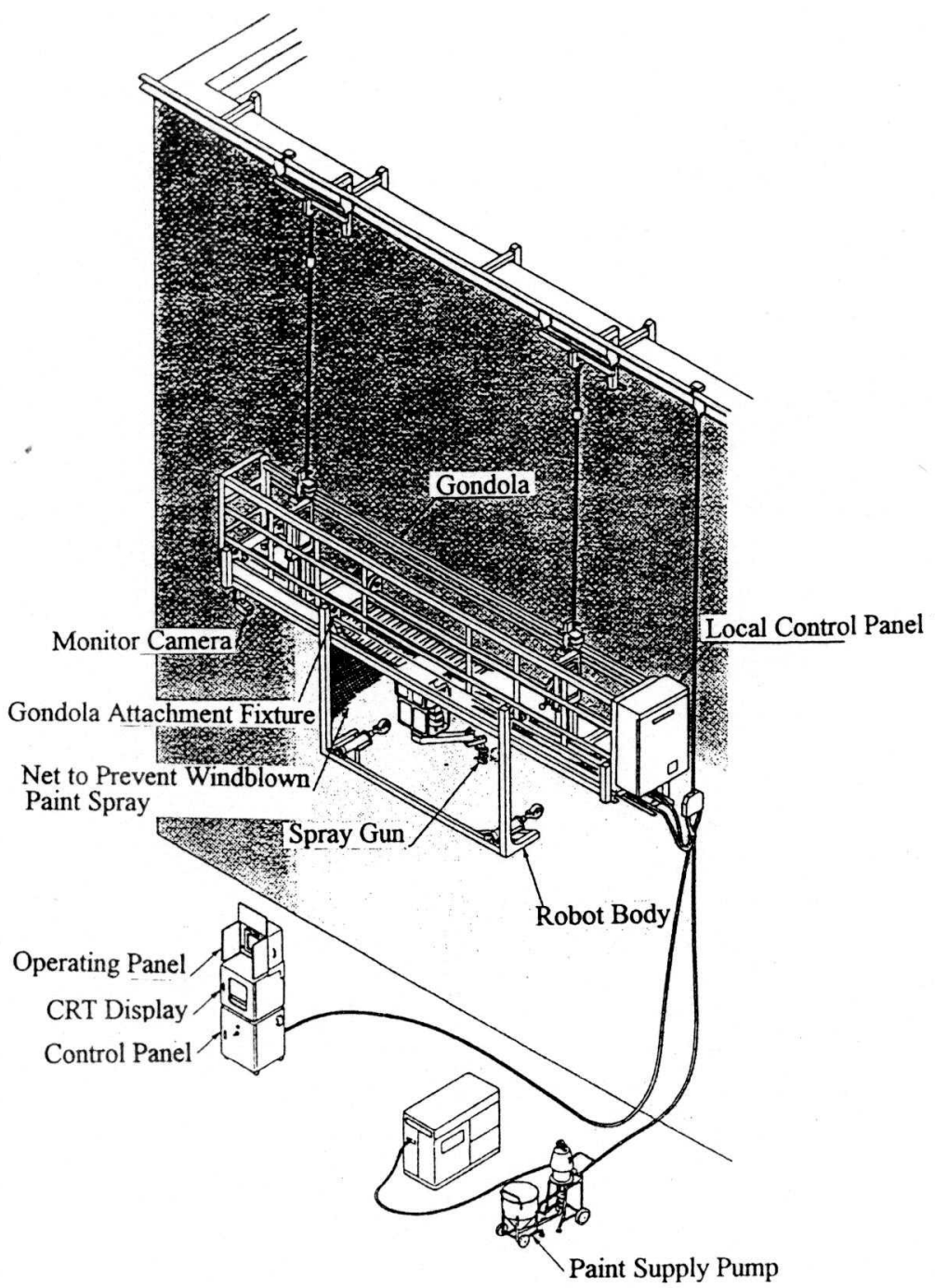

Figure 1 Painting Robot System

Table 1 Painting Robot Specifications

\begin{tabular}{|c|c|c|}
\hline \multicolumn{2}{|r|}{ Item } & Specification \\
\hline \multirow[t]{4}{*}{ Moving Device } & Moving Device & Gondola Staging \\
\hline & Suspension Distance & $3.6 \mathrm{~m}$ \\
\hline & Up and Down Speed & $5 \mathrm{~m} / \mathrm{min}$ \\
\hline & Traversing Speed & $3 \mathrm{~m} / \mathrm{min}$ \\
\hline \multirow[t]{7}{*}{ Robot } & Paint Material & Multí-layer Type Acrylic Waterproof Coatin \\
\hline & Maximum Painting Width & $4 \mathrm{~m}$ Horizontal \\
\hline & Productivity & $\begin{array}{l}\text { Under and Top Coats : } 230 \mathrm{~m}^{2} / \mathrm{h} \\
\text { Intermediate Coat }: 160 \mathrm{~m}^{2} / \mathrm{h} \\
\text { Body Texture Coat }: 130 \mathrm{~m}^{2} / \mathrm{h}\end{array}$ \\
\hline & Gun Moving Speed & $40 \mathrm{~m} / \mathrm{min} \quad$ Horizontal \\
\hline & Gun Rotation Angle & Lateral : $\pm 90^{\circ}$ Vertical : $\pm 45^{\circ}$ \\
\hline & Dimensions & (L) $5.4 \mathrm{~m} \times(\mathrm{W}) 0.8 \mathrm{~m} \times(\mathrm{H}) 1.5 \mathrm{~m}$ \\
\hline & Weight & $340 \mathrm{~kg}$ (Attached to the Gondo \\
\hline
\end{tabular}




\section{PERFORMANCE VERIFICATION TRIAL}

\subsection{Outline of the Trial}

In order to determine the best conditions for actual painting work, it was decided to focus attention during the trials on application of the intermediate and body texture coats in which problems of unevenness and sagging often occur.

Two types of paint generally used in industrial applications were used for the trials. The spray gun, painting speed and distance from the surface to be painted were fixed, and the test parameters were the viscosity of the paint, delivery pressure of the paint supply pump, and spray air pressure.

\subsection{Trial Results}

The optimum conditions for spraying external walls using this robot are given in Table 2. By controlling the viscosity of the paint, with a fixed pumping pressure and air pressure, it was confirmed that the paint spraying operation, from under coat to top coat, could be carried out with uniform quality.

It was found that the required thickness of intermediate paint film could be achieved by controlling the paint supply pump pressure. To achieve the required thickness (wet thickness $0.8 \mathrm{~mm}$ ) in the case of paint type A, a pump pressure of $100 \mathrm{kgf} / \mathrm{cm}^{2}$ was required, and for paint type B, the required pressure was found to be $60 \mathrm{kgf} / \mathrm{cm}^{2}$. It was found that by controlling the air pressure during the application of the body texture coat, it was possible to produce a bead pattern of the required diameter over a range from small to large. A large texture (average diameter of $10 \mathrm{~mm}$ ) could be achieved with an air pressure of $3 \mathrm{kgf} / \mathrm{cm}^{2}$.

It was also found that the various control parameters need only be pre-set initially for each painting operation performed by the robot.

Table 2 Robot Optimum Painting Conditions

\begin{tabular}{|l|l|c|c|c|c|}
\hline \multicolumn{2}{|c|}{ Item } & Under Coat & $\begin{array}{l}\text { Intermediate } \\
\text { Coat }\end{array}$ & $\begin{array}{l}\text { Body Texture } \\
\text { Coat }\end{array}$ & Top Coat \\
\hline General & Spray Method & Airless Spray & Air Spray & Air Spray & Airless Spray \\
& Spray Distance (mm) & 500 & 500 & 500 & 500 \\
& Painting Speed (m/min) & 40 & 40 & 40 & 40 \\
\hline Paint A* & Viscosity Control Value** (poise) & 0.3 & 140 & 270 & 0.8 \\
& Delivery Pressure (kgf/cm $)$ & 80 & 100 & 100 & 80 \\
& Spray Air Pressure (kgf/cm²) & - & 6.5 & $3.0 \sim 4.5$ & - \\
\hline Paint B* & Viscosity Control Value** (poise) & 0.3 & 90 & 180 & 1 \\
& Delivery Pressure (kgf/cm²) & 80 & 60 & 70 & 80 \\
& Spray Air Pressure (kgf/cm $\left.{ }^{2}\right)$ & - & 6.5 & $2.5 \sim 5.0$ & - \\
\hline
\end{tabular}

\section{WORKING TRIALS}

\subsection{Outline of the Trials}

Painting trials were carried out on nuclear power station buildings and the performance of the robot and quality of the paint work were verified, (see Photo 1).

The trials were performed on an external concrete wall over an area of 
approximately $570 \mathrm{~m}^{2}$ using type B paint with the conditions indicated in Table 2 . As there are indentations and protrusions in the external wall due to structural columns etc., the painting was carried out by dividing the surface into spans of $3 \mathrm{~m}$ to $4 \mathrm{~m}$ in width. A protective net was provided over the entire wall area to prevent the paint spray from being windblown, and to prevent the robot from swaying due to strong winds.

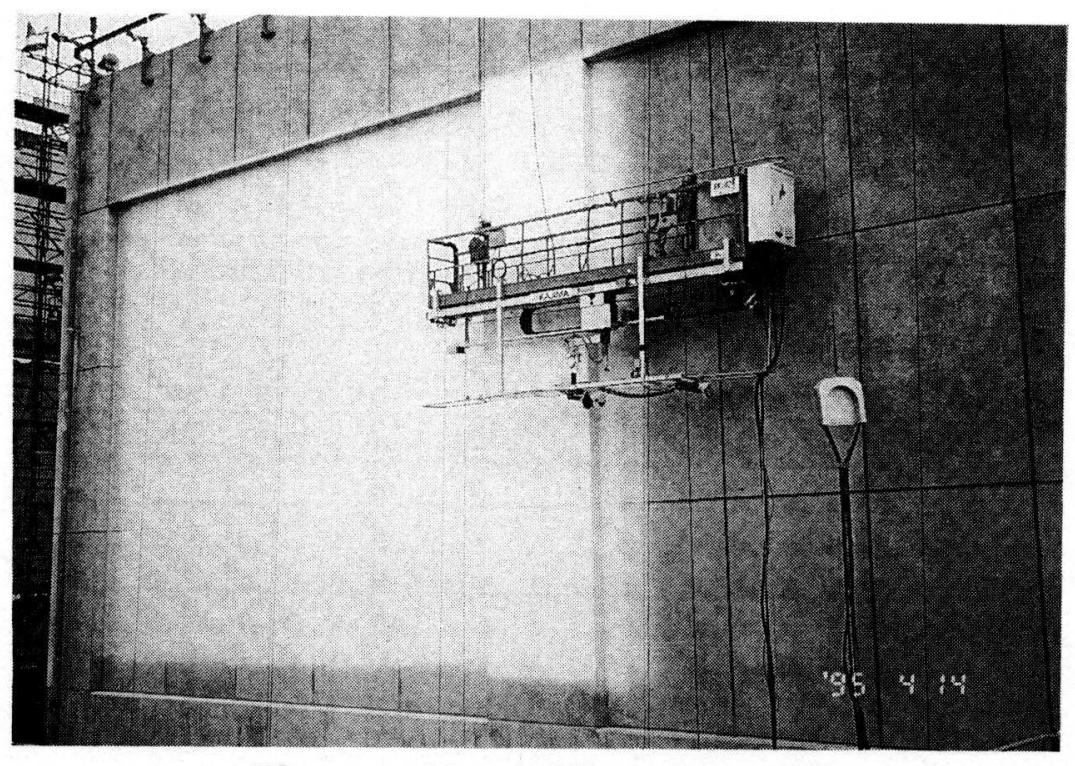

Photo 1 View of Painting Trial

\subsection{Results of the Trials}

In Figure 2 is shown the results of measurements of the thickness of paint work performed by robot compared with those where the work was performed manually. It was found that the robot achieved the same level of quality as the experienced craftsman, in particular, it was confirmed that there were no regions in the area painted by the robot where the target thickness of $0.9 \mathrm{~mm}$ was not achieved. It was also found that quality of finish was maintained at the overlap of adjoining spans (span width $3 \sim 4 \mathrm{~m}$ ).

With regard to the productivity, it was found that, including the movement of the gondola, the intermediate coat could be applied at a rate of approximately $200 \mathrm{~m}^{2} / \mathrm{h}$, and that the body texture coat could be applied at approximately $150 \mathrm{~m}^{2} / \mathrm{h}$. A comparison of the productivity of painting work performed by the robot with that achieved by a craftsman is shown in Table 3. However, this comparison is for the work of one robot against the work of one man, and does not include assembly, adjustment and dismantling of the robot, i.e., the comparison is limited to the painting work alone.

This result demonstrates that the performance of the robot is more than four times that of a craftsman. In particular, the high performance of the robot was proven with regard to the application of the intermediate coat and body texture coat which both demand a high level of technical skill. Therefore, it can be assumed that the larger the surface area to be painted the greater will be the benefit of using the robot. 


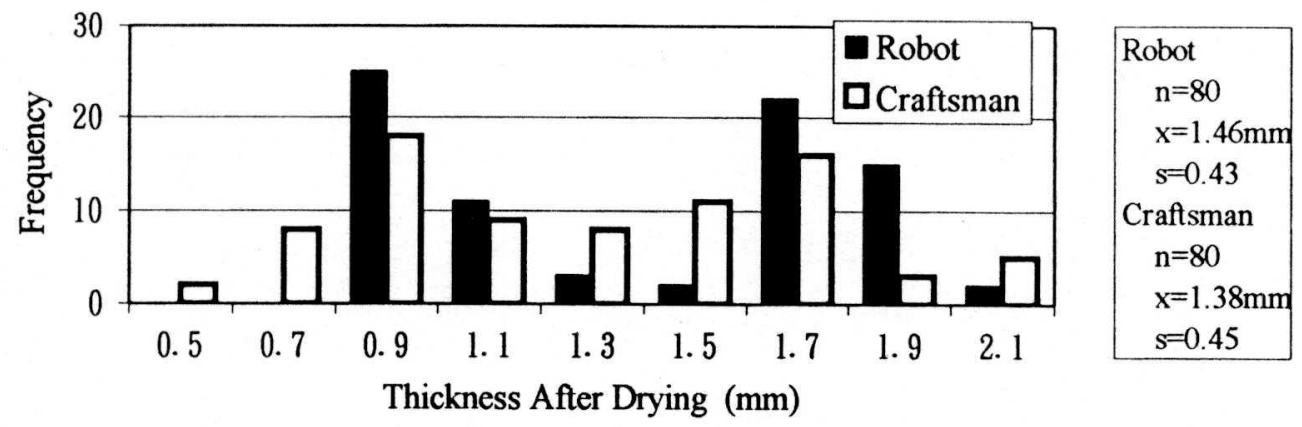

Figure 2 Trial Paint Thickness Distribution

Table 3 Productivity Comparison - Robot vs. Craftsman

\begin{tabular}{|c|c|c|c|}
\hline Painting Process & Robot (one unit) & Craftsman (one man) & Productivity Ratio \\
\hline Under and Top Coats & $290 \mathrm{~m}^{2} / \mathrm{h}$ & $65 \mathrm{~m}^{2} / \mathrm{h}$ & 4.5 \\
\hline Intermediate Coat & $205 \mathrm{~m}^{2} / \mathrm{h}$ & $28 \mathrm{~m}^{2} / \mathrm{h}$ & 7.3 \\
\hline Body Texture Coat & $149 \mathrm{~m}^{2} / \mathrm{h}$ & $22 \mathrm{~m}^{2} / \mathrm{h}$ & 6.8 \\
\hline
\end{tabular}

\subsection{Remaining Technical Problems}

From the trials the following technical problems remain to be coped with:

i) Variation in the viscosity of the intermediate coating causes unevenness; therefore, a means of controlling the viscosity is necessary.

ii) Painting of the jambs associated with indentations and protrusions such as columns is difficult, and the existing method needs to be improved.

\section{CONCLUSION}

Painting trials were carried out with the newly developed painting robot designed for use with gondola staging, on nuclear power station buildings. As a result of these trials, the performance of the robot and quality of the painting work were confirmed to be of good standard. It is now planned to improve and modify the system to increase adaptability to make it suitable for widespread use.

\section{REFERENCES}

1. S. Terauchi, T. Miyajima, T. Miyamoto, and K. Arai, "Development of an Exterior Wall Painting Robot Capable of Painting Walls with Indentations and Protrusions," Proc. 10th International Symposium on Automation and Robotics in Construction, 1993. 